\title{
CALCÁRIO E SUA INFLUÊNCIA NO CULTIVO DE MANDIOCA NA AMAZÔNIA TOCANTINA
}

\author{
Jefferson dos Santos Martins ${ }^{1}$, Mariana Casari Parreira², Rafael Coelho Ribeiro ${ }^{3}$, Evaldo \\ Morais da Silva ${ }^{4}$
}

\begin{abstract}
RESUMO - O cultivo de raízes de mandioca é muito importante nas regiões do Brasil, principalmente por pessoas de baixa renda. Apesar do aumento da área plantada, a produtividade desta cultura é baixa, devido principalmente à baixa fertilidade e manejo dos solos utilizados para o plantio. Este trabalho teve como objetivo avaliar a influência do calcário na cultura da mandioca no Nordeste Paraense (Amazônia Tocantina). O experimento foi realizado sob condições de campo, no período de novembro de 2015 a setembro de 2016, em uma propriedade rural de caráter familiar no município de Cametá, estado do Pará. O experimento foi conduzido em delineamento em blocos casualizados - DBC, com quatro repetições. Os tratamentos utilizados foram dosagens crescentes de calcário: $500 \mathrm{~kg} \mathrm{ha}^{-1} ; 750 \mathrm{~kg} \mathrm{ha}^{-1} ; 1.000 \mathrm{~kg} \mathrm{ha}^{-1} ; 1.500 \mathrm{~kg} \mathrm{ha}^{-1}$, mais uma testemunha sem aplicação. A cultura foi conduzida de acordo com os produtores familiares da Amazônia Tocantina, sem irrigação e adubação complementares. Foram avaliados: comprimento, diâmetro, número e peso de raízes por planta, produção total de raízes e também a quantificação de ácido cianídrico. Verificou-se que o maior peso de raízes por planta e a máxima produção foram obtidos utilizando a menor dosagem. A quantidade de ácido cianídrico nas raízes não foi diminuída com o aumento das doses de calcário, sendo a cultivar utilizada, classificada como mandioca mansa ou de mesa.
\end{abstract}

Palavras chave: calagem, cianogênico, Manihot esculenta Crantz, produtividade.

\section{LIMESTONE INFLUENCE ON CASSAVA CROP IN TOCANTINA AMAZON}

\begin{abstract}
The cassava roots crop is very important in the regions of Brazil, especially by low income people. Despite the increase in planted area, the productivity of this crop is low, mainly due to the low fertility and soil management used for planting. The objective of this work was to evaluate the influence of limestone on the cassava crop in the Northeast of Pará (Amazon Tocantina).The experiment was conducted under field conditions, from November 2015 to September 2016, in a rural property of a family character in Cametá$\mathrm{Pa}$. The experiment was conducted in a randomized complete block design (DBC), with four replications. The treatments used were increasing dosages of limestone: $500 \mathrm{~kg} \mathrm{ha}^{-1} ; 750 \mathrm{~kg} \mathrm{ha}^{-1} ; 1,000 \mathrm{~kg} \mathrm{ha}^{-1} ; 1,500$ $\mathrm{kg} \mathrm{ha}^{-1}$, plus one control test. The length, diameter, number and weight of roots per plant, total root production and the quantification of hydrocyanic acid were evaluated. It was verified that the highest root weight per plant and maximum yield were obtained using the lowest limestone dosage. The amount of hydrocyanic acid in the roots was not decreased with the increase of limestone doses, being the cultivar used, classified as calm cassava.
\end{abstract}

Keywords: Keywords: cyanogenic, liming, Manihot esculenta Crantz, productivity.

${ }^{1}$ Faculdade de Agronomia (FAGRO). Campus Universitário do Tocantins (CUNTINS). Universidade Federal do Pará. UFPA. Email: 1santos-jeff@hotmail.com.2mcparreira@ufpa.br.3rribeiro@ufpa.br.4evaldo.morais@ufpa.br 


\section{INTRODUÇÃO}

A raiz tuberosa da mandioca (Manihot esculenta Crantz), em diversas regiões do Brasil, é a principal fonte nutricional das populações de baixa renda, sendo muito cultivada por pequenos agricultores, com baixa tecnologia (Roset et al., 2011), principalmente por ser um alimento básico prontamente disponível, ter facilidade de cultivo e capacidade de transformação podendo ser armazenado como alimento por vários anos (Nassar et al., 2009).

A Amazônia Tocantina, localizada no Nordeste Paraense juntamente com o Baixo Amazonas concentram as maiores áreas cultiváveis e produção de mandioca do Estado do Pará, assim como também registraram as mais altas expansões desta atividade (Gusmão et al., 2016). Apesar do aumento na área plantada, a produtividade, segundo Alves \& Modesto Junior (2012) está diminuindo, devido à dificuldade de modernização da produção, oferta reduzida de tecnologia e assistência técnica aos produtores, falta de mão de obra e redução ao acesso de financiamentos de suas atividades agrícolas.

Outro fator relevante dessa baixa produtividade está relacionado à fertilidade e manejo dos solos utilizados para o plantio, visto que, grande parte das classes de solo presentes na região são de fertilidade natural baixa, com altas concentrações de alumínio, que os classificam como solos ácidos (Alves et al., 2008).

Ainda que a mandioca apresente resistência à saturação de alumínio em até 80\% (Nassar et al., 2009), a calagem faz-se necessária, principalmente pela aplicação de calcário, adequando a faixa de $\mathrm{pH}$ e que consequentemente subsidia a absorção dos nutrientes disponibilizados no solo para a planta (Serrat et al., 2002).

Apesar do papel social que desempenha a cultura da mandioca no Estado do Pará, pelo número representativo de famílias do meio rural que vivem da produção e também do processamento da farinha (Mattos \& Cardoso, 2017), este cultivo realizado a partir de uma planta cianogênica (Haque \& Bradbury, 2002), no qual há restrição no consumo das suas raízes em decorrência da quantidade de ácido cianídrico (HCN) naturalmente armazenado em suas cultivares. Todavia, o processo fitoquímico da liberação de cianeto (CN) através da hidrolise de compostos cianogênicos, é um defensivo natural da planta contra o ataque de moléstias peculiares à cultura (El-Sharkawy, 2012). Assim sendo, objetivou-se com este trabalho avaliar a influência do calcário na cultura da mandioca no Nordeste Paraense (Amazônia Tocantina).

\section{MATERIALE MÉTODOS}

O presente trabalho foi realizado sob condições de campo, no período de novembro de 2015 a setembro de 2016, em uma propriedade rural de caráter familiar na Comunidade Livramento (2 $2^{\circ} 17^{\prime} 49^{\prime \prime} \mathrm{S}-49^{\circ} 37^{\prime} 06^{\prime \prime} \mathrm{W}$ ) localizada no município de Cametá $\left(2^{\circ} 14\right.$ ' $32^{\prime \prime} \mathrm{S}-49^{\circ}$ 29' 52”W) na Amazonia Tocantina. Os dados climatológicos relativos às temperaturas e a precipitação pluviométrica durante a preparação do solo e a manutenção do plantio, encontram-se na Figura 1.

No preparo da área experimental, levou-se em consideração o modo de cultivo empregado, tradicionalmente, pela comunidade rural no plantio da mandioca da região da Amazônia Tocantina, ou seja, a área foi inicialmente submetida ao processo de cortequeima para a limpeza do espaço e posteriormente, parcialmente destocada. Decorridos três dias após o preparo do campo experimental, coletou-se uma amostragem de solo para a determinação das características químicas e físicas, exibidas nas Tabelas 1 e 2.

Após a preparação do terreno descrita anteriormente, foram depositadas uniformemente, de forma manual as quantidades de calcário de acordo com o tratamento. Foi utilizado calcário dolomítico (32\% $\mathrm{CaO}$ e $17 \% \mathrm{MgO})$. Após a deposição do produto, a área permaneceu em pousio por três meses, a fim de que ocorresse o cumprimento do prazo necessário para que o corretivo realizasse com eficiência a diminuição da acidez do solo (Serrat et al., 2002).

Utilizou-se a cultivar de mandioca Vermelhinha, possuindo ciclo precoce (em torno de seis a oito meses), sendo uma das cultivares mais empregadas pelos agricultores da comunidade da região. O plantio foi realizado de forma manual, no qual foram empregadas manivas sadias com o comprimento em torno de 20 $\mathrm{cm}$, integrando de 5 a 7 gemas. Elas foram depositadas no sentido horizontal em covas com profundidade aproximada de $10 \mathrm{~cm}$ (Alves et al., 2008).

O experimento foi conduzido em delineamento em blocos casualizados - DBC, com 5 tratamentos, nas 


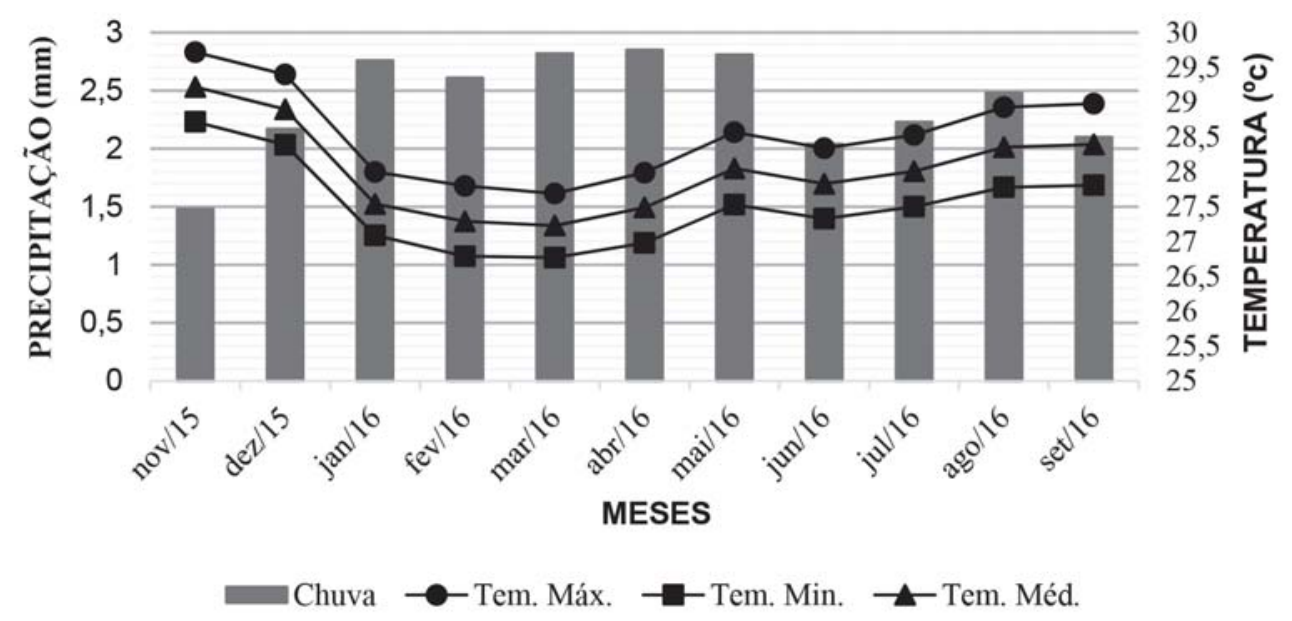

Figura 1 - Temperaturas máximas, mínimas, médias e precipitações pluviais médias apuradas de novembro de 2015 a setembro de 2016 em Cametá, PA.

Tabela 1 - Composição química do solo na área experimental, Cametá-PA

\begin{tabular}{lcccccccccccc}
\hline $\mathrm{MO}$ & $\mathrm{pH}$ & $\mathrm{P}$ & $\mathrm{K}$ & $\mathrm{Na}$ & $\mathrm{Ca}$ & $\mathrm{Ca}+\mathrm{Mg}$ & $\mathrm{Al}$ & $\mathrm{H}+\mathrm{Al}$ & $\mathrm{CTC}$ & & Saturação \\
\hline (g/kg) & (Água) & & $\left(\mathrm{mg} / \mathrm{dm}^{3}\right)$ & & $\left(\mathrm{cmol}_{\mathrm{c}} / \mathrm{dm}^{3}\right)$ & & & $\begin{array}{c}\text { Total } \\
\left(\mathrm{cmol}_{\mathrm{c}} / \mathrm{dm}^{3}\right)\end{array}$ & Efetiva & Base(V\%) & Alumínio(m\%) \\
18,14 & 3,8 & 5 & 30 & 19 & 0,5 & 0,7 & 1,2 & 8,75 & 9,6 & 2,06 & 8,93 & 58,34 \\
\hline
\end{tabular}

Fonte: EMBRAPA, 2016.

Tabela 2 - Composição física do solo na área experimental, Cametá-PA

\begin{tabular}{cccc}
\hline \multicolumn{3}{c}{ Granulometria } \\
\hline Areia grossa(g/kg) & Areia fina $(\mathrm{g} / \mathrm{kg})$ & Silte $(\mathrm{g} / \mathrm{kg})$ & Argila total(g/kg) \\
462 & 344 & 74 & 120 \\
\hline
\end{tabular}

Fonte: EMBRAPA, 2016.

dosagens: $500 \mathrm{~kg} \mathrm{ha}^{-1}, 750 \mathrm{~kg} \mathrm{ha}^{-1}, 1.000 \mathrm{~kg} \mathrm{ha}^{-1}, 1.500$ $\mathrm{kg} \mathrm{ha}^{-1}$, mais uma testemunha sem aplicação de calcário, com quatro repetições. Cada unidade experimental era composta por parcelas de 2,0 m de largura por 4,0 m de comprimento, sendo constituída por três linhas com plantas em espaçamento de $1,0 \mathrm{~m}$ x 1,0 m. Lançando mão do efeito bordadura, foram descartadas as plantas de cada extremidade, sendo avaliadas somente as plantas centrais.

A cultura foi conduzida de acordo com os produtores familiares da Amazônia Tocantina, em que não ocorreu aplicação de defensivos agrícolas e adubação, como também ausência de irrigação suplementar. Os tratos culturais foram realizados após três meses (90 DAP) da instalação do plantio, sendo capinas manuais (Alves et al., 2008).

Transcorridos os seis meses ao plantio (180 DAP), ocorreu a colheita da cultura, também de forma manual, onde as raízes foram colhidas por meio do arranquio. Nesse momento, foram avaliados os componentes de produção e também as amostras para a quantificação do ácido cianídrico, descritos a seguir:

\section{Parâmetros de produção avaliados:}

Para determinar os componentes de produção, foram avaliados: comprimento de raízes, diâmetro de raízes, número de raízes por planta, pesos de raízes por planta e produção total de raízes. 
O número médio de raízes por planta foi determinado pela divisão do número total de raízes extraídas por parcela pelo número de plantas colhidas em cada uma delas. Para o comprimento e o diâmetro foram selecionadas, de cada planta colhida na sua respectiva parcela, três raízes com características morfológicas semelhantes. Em seguida, com a utilização de uma régua graduada, determinou-se o comprimento através da medição de uma extremidade a outra da raiz. Já o diâmetro foi apurado na região mediana da raiz (terço médio) com a assistência de um paquímetro analógico (Gonzales et al., 2014).

O peso médio de raízes por planta foi determinado por meio de uma balança eletrônica, com a qual se realizou a pesagem do total de raízes em cada planta por parcela. Posteriormente, calculou-se a média dos pesos aferidos e dividiu-se o valor pelo número de plantas colhidas em cada uma das parcelas (Aguiar et al., 2011). Os resultados obtidos dos componentes de produção foram submetidos à análise de variância (teste F) e as médias foram comparadas pelo teste Tukey a 0,05 de significância.

\section{Determinação do teor de ácido cianídrico (HCN):}

Depois de avaliados os componentes de produção, amostras compostas de cada tratamento foram enviadas para o laboratório Centro de Qualidade Analítica LTDA, de acordo com a metodologia descrita por Aguiar (2003), para a quantificação dos compostos cianogênicos nas raízes, com o propósito de avaliar o efeito das doses de calcário sobre o teor de HCN e classificar a cultivar utilizada. Para tanto, utilizou-se o parâmetro classificatório relatado por Borges et al. (2002), descrito na Tabela 3.

\section{RESULTADOS E DISCUSSÃO}

\section{Componentes de produção}

O comprimento e diâmetro das raízes não foram influenciados pela quantidade de calcário aplicada no período experimental, possuindo as raízes comprimento médio de 28 cm e 4,4 centímetros de diâmetro (Tabela 4). Silva et al. (2013) ao utilizar a calagem em áreas

Tabela 3 - Classificação de raízes de mandioca quanto ao teor de compostos cianogênicos

\begin{tabular}{cc}
\hline Classificação & HCN $\left(\right.$ mgkg $^{-1}$ de polpa fresca $)$ \\
\hline Mansa ou de mesa & $<100$ \\
Brava ou tóxica & $>100$ \\
\hline
\end{tabular}

cultivadas com mandioca, também não constatou influência do calcário nas raízes de mandioca.

Entretanto Carvalho et al. (2007) descreve haver efeito positivo no comprimento e diâmetro de raízes de mandioca nas concentrações de 1500 e 3000 (kg ha $^{-1}$ ) de calcário dolomítico. Do mesmo modo, Oliveira et al. (2012), ao testar níveis diferentes do macronutriente nitrogênio $(\mathrm{N})$, percebeu comportamento linear entre as dosagens utilizadas e parâmetros analisados como produção e comprimento de raízes. Silva et al. (2017), ao submeter a cultura da mandioca a diferentes dosagens de macronutrientes, incluindo o potássio, também presenciou o acréscimo em diâmetro das raízes.

A quantidade de raízes por planta de mandioca também não foi influenciada pelos tratamentos variando de 3 a 5 raízes por planta (Tabela 4). Tais resultados contrariam aqueles obtidos por Alves et al. (2012) em pesquisa similar, onde a elevação na dose de calcário implicou em aumento proporcional do número médio de raízes por planta.

A calagem afetou a massa fresca das raízes (Tabela 5), diferente do que correu com os outros parâmetros. Ao se comparar com as plantas que não tiveram acesso ao calcário (testemunha), o tratamento com a menor dose (500 kg ha-1) proporcionou raízes mais pesadas, com até $36,6 \%$ de incremento, entretanto as raízes submetidas a $1500 \mathrm{~kg} \mathrm{ha}^{-1}$ (maior dosagem) o peso das raízes reduziu $8,3 \%$.

Silva et al. (2004), avaliando a influência do calcário dolomítico (0 e $2000 \mathrm{~kg} \mathrm{ha}^{-1}$ ) e mais o elemento fósforo, em diversas cultivares de mandioca, também verificaram aumento no peso das raízes, ao adicionar estes macronutrientes ao solo.A calagem também proporcionou maior crescimento inicial e desenvolvimento da parte aérea das plantas, em resposta ao aumento das doses de calcário conforme observado em pesquisa semelhante, realizada em Assis, no interior de São Paulo (Brancalião et al., 2015).

Analisando a produção total das plantas de mandioca (Tabela 5), ao utilizar a menor dose de calcário (500 kg ha-1), a produção das raízes foi máxima, ultrapassando quatro quilos. O tratamento com a maior dosagem utilizada (1500 kg ha-1) não promoveu diferença, em relação à testemunha (ausência de calcário), que foi em torno de $2,4 \mathrm{~kg}$. 
Tabela 4 - Comprimento, diâmetro das raízes e número de raízes por planta de mandioca em função de diferentes doses de calcário, Cametá-PA

\begin{tabular}{|c|c|c|c|}
\hline Dose de calcário & Comprimento & Diâmetro & Raízes/Planta \\
\hline$\left(\mathrm{kg} \mathrm{ha}^{-1}\right)$ & & & $\left(\mathrm{N}^{\circ}\right)$ \\
\hline 0 & 27,97 & 4,25 & 4 \\
\hline 500 & 27,15 & 4,6 & 5,02 \\
\hline 750 & 28,87 & 5,17 & 4,25 \\
\hline 1000 & 26,65 & 4,37 & 3,92 \\
\hline 1500 & 29,45 & 3,85 & 4,75 \\
\hline $\mathrm{F}$ & $0,22 \mathrm{~ns}$ & $2,01 \mathrm{~ns}$ & $1,45 \mathrm{~ns}$ \\
\hline Coeficiente de variação & 17,73 & 15,47 & 18,17 \\
\hline
\end{tabular}

Médias seguidas de letras iguais, não diferem significativamente entre si pelo teste de Tukey ao nível de 5\% de probabilidade.

Tabela 5 - Massa seca das raízes e Produção total do cultivo de mandioca em função de diferentes dosagens de calcário, Cametá- PA

\begin{tabular}{ccc}
\hline Dose de calcário & Raiz/planta & Produção total \\
\hline$\left(\mathrm{kg} \mathrm{ha}^{-1}\right)$ & & $(\mathrm{kg})$ \\
\hline 0 & $0,60 \mathrm{ab}$ & $2,40 \mathrm{~b}$ \\
750 & $0,80-\mathrm{a}$ & $4,29 \mathrm{a}$ \\
1000 & $0,67 \mathrm{ab}$ & $2,78 \mathrm{~b}$ \\
1500 & $0,75 \mathrm{ab}$ & $2,83 \mathrm{ab}$ \\
$\mathrm{F}$ & $0,55 \mathrm{~b}$ & $2,58 \mathrm{~b}$ \\
Desvio padrão & $3,35 *$ & $5,31 *$ \\
Coeficiente de variação & 0,13 & 0,65 \\
\hline
\end{tabular}

Médias seguidas de letras iguais, não diferem significativamente entre si pelo teste de Tukey ao nível de 5\% de probabilidade. *Significativo a $5 \%$ de probabilidade pelo teste $\mathrm{F}$.

Este dado evidencia que, na região onde foi instalado o experimento, não é necessária a aplicação de altas doses de calcário para elevar a produtividade, evitando assim custos desnecessários para os produtores, no entanto, a operação de calagem deve ser feita, caso se constate que o solo necessite como ocorreu neste trabalho que está exemplificado na Tabela 1.

Nesse mesmo contexto Alves Filho et al. (2015), descrevem que a combinação de doses baixas de calcário e zinco apresentaram aumento relevante na produção da mandioca. Entretanto, Brancalião et al. (2015), em Latossolo Vermelho Distrofico, verificaram aumento no crescimento e no desenvolvimento da parte aérea e raízes das plantas somente com doses muito altas, superior a $4000 \mathrm{~kg} \mathrm{ha}^{-1}$ de calcário.

\section{Ácido cianídrico (HCN)}

Ao quantificar o conteúdo de ácido cianídrico nas raízes de mandioca (Tabela 6), constatou-se que o aumento das dosagens de calcário aplicadas durante a calagem, não reduziu a quantidade de ácido cianídrico nas raízes, sendo obtido dos tratamentos o valor médio de 0,3 mg de HCN por kg. De acordo com a Tabela 2, a cultivar utilizada nesse experimento (Vermelhinha), se enquadra na classe de raízes mansa ou de mesa. Em discordância com Azevedo (1992), que qualifica a cultivar como brava ou tóxica.

Todavia, os dados obtidos através da análise laboratorial foram discrepantes. Isto pode estar relacionado ao procedimento metodológico no momento da coleta e preparação das amostras ou no deslocamento e acondicionamento. Uma vez que, em consonância a Borges et al. (2002), a carência de metodologias mais específicas e pouco onerosas para a quantificação do ácido cianídrico em plantas de mandioca ainda é uma das principais limitações para obtenção de informações precisas acerca desta importante característica vegetal. 
Tabela 6 - Quantificação de ácido cianídrico em raízes de mandioca sob efeito da calagem, Cametá, PA

\begin{tabular}{cc}
\hline Dose de calcário & HCN \\
\hline$\left(\mathrm{kg} \mathrm{ha}^{-1}\right)$ & $\left(\mathrm{mgkg}^{-1}\right)$ \\
0 & $* \mathrm{LQ}$ \\
500 & 0,63 \\
750 & $* \mathrm{LQ}$ \\
1000 & 0,57 \\
1500 & 0,12 \\
\hline
\end{tabular}

*LQ: menor que o limite de quantificação de $0,05 \mathrm{mg} / \mathrm{kg}$. Fonte: Centro de Qualidade Analítica LTDA, 2016.

\section{CONCLUSÃO}

O maior peso de raízes por planta e a produção total máxima das plantas de mandioca foram obtidas utilizando a menor dosagem de calcário (500 kg ha$\left.{ }^{1}\right)$ durante a calagem, sendo a cultivar utilizada classificada como mansa ou de mesa.

\section{LITERATURACITADA}

AGUIAR, E.B. Produção e qualidade de mandioca de mesa (Manihot esculenta Crantz) em diferentes densidades populacionais e épocas de colheita. Dissertação (Mestrado em Agricultura Tropical e Subtropical). Instituto Agronômico de Campinas, Campina, SP, 2003. 90p.

AGUIAR, E.B. et al. Efeito da densidade populacional e época de colheita na produção de raízes de mandioca de mesa. Bragantia, v.70, n.3, p.561-569, 2011.

ALVES FILHO, P.P.C. et al. Resposta da cultivar de mandioca roxinha à adubação NPK. Revista Raízes e Amidos Tropicais, v.11, n.1, p.1-7, 2015.

ALVES, R.N.B. et al. O Trio da Produtividade na Cultura da Mandioca: Estudo de caso de adoção de tecnologias na região no Baixo Tocantins, estado do Pará. In: CONGRESSO DAABIPTI, 2008. Anais...Campina Grande PB, ABIPTI, junho, 2008. 1.CD-ROM.

ALVES, R.N.B.; MODESTO JÚNIOR, M.S. Custo e rentabilidade do processamento de farinha de tapioca no distrito de americano, município de Santa Isabel do Pará, Pará. Amazônia: Ciência e Desenvolvimento, Belém, PA, v.8, n.15, p.7-18, 2012.
ALVES, R.N.B. et al. Doses de NPK na adubação de Mandioca (Manihotesculenta, L) variedade Paulozinho em Moju-Pará. Revista Raízes e Amidos Tropicais, v.8, p.65-70, 2012.

AZEVEDO, J.N. Cultivares de mandioca bravas e mansas recomendadas para o Piauí. Comunicado Técnico.

Teresina, PI:EMBRAPA/unidade de Execução de Pesquisa de Âmbito Estadua1 de Teresina UEPAE de Teresina, 1992. 4p.

BORGES, M.F.; FUKUDA, W.M.; ROSSETTI, A.G. Avaliação de variedades de mandioca para consumo humano. Pesquisa Agropecuária Brasileira, v.37, n.11, p.1559-1565, 2002.

BRANCALIAO et al. S.R. Crescimento e desenvolvimento de plantas de mandioca em função da calagem e adubação com zinco.

Nucleus, v.12, n.2, 2015.

CARVALHO, F.M. et al. Manejo do solo em cultivo com mandioca em treze municípios da região sudeste da Bahia. Ciência e Agrotecnologia, v.31, p.378-384, 2007.

EL-SHARKAWY, M.A. Stress-tolerant cassava: the role of integrative ecophysiology-breeding research in crop improvement. Open

Journal of Soil Science, v.2, n.2, p.162186, 2012.

GONZALES, P.F. et al. Componentes de produção e morfologia de raízes de mandioca sob diferentes preparos do solo. Bragantia, v.73, n.4, p.357-364, 2014.

GUSMAO et al. Análise cartográfica da concentração do cultivo de mandioca no estado do Pará, Amazônia brasileira.

Geografia, Ensino \& Pesquisa, v.20, n.3, p.51-62, 2016.

HAQUE, M.R.; BRADBURY, J.H. Total cyanide determination of plants and foods using the picrate and acid hydrolysis methods. Food Chemistry, v.77, p.101-114, 2002. 
MATTOS, P.L.P.; CARDOSO, E.M.R. Cultivo da mandioca para o Estado do Pará. Disponível em: m:<http://

sistemasdeproducao.cnptia.embrapa.br/

FontesHTML/Mandioca/mandioca_para/ mercado.htm>. Acesso em 15/03/2017.

NASSAR, N.M. et al. Improving carotenoid sandamino-acids in cassava. Recent Patents on Food, Nutrition \& Agriculture, v.1, n.1, p.32-38, 2009.

OLIVEIRA, N.T. et al. Ácido cianídrico em tecidos de mandioca em função da idade da planta e adubação nitrogenada. Pesquisa Agropecuária

Brasileira, v.47, n.10, p.1436-1442, 2012.

RÓS, A.B.; HIRATA, A.C.S.; DE ARAÚJO, H.U.; NARITA, N. Crescimento, fenologia e produtividade de cultivares de mandioca.

Pesquisa Agropecuária Tropical, v.41, n.4, p.552-558, 2011.
SERRAT, B.M. et al. Conhecendo o solo. Universidade Federal do Paraná. Departamento de Solos e Engenharia Agrícola. Projeto de Extensão Universitária Solo Planta. Curitiba: UFPR, 2002. 17p.

SILVA, A.S. et al. Atributos químicos do solo e produtividade de mandioca em função da calagem, adubação orgânica e potássica. $2^{\circ}$ Simpósio de Integração Científica e Tecnológica do Sul Catarinense - SICT-Sul, v.1, n.1, p.86-92, 2013.

SILVA, D.C.O. et al. Curvas de crescimento de plantas de mandioca submetidas a doses de potássio. Revista de Ciências Agrárias, v. 60, n. 2, p. 158-165. 2017.

SILVA, G.G.C. et al. Toxicidade cianogênica em partes da planta de cultivares de mandioca cultivados em Mossoró-RN. Revista Ceres, v.51, p.56-66, 2004.

Recebido para publicação em 9/1/2018 e aprovado em 2/3/2018. 